\title{
Agent Based Modeling of Air Carrier Behavior for Evaluation of Technology Equipage and Adoption
}

\author{
Brant M. Horio ${ }^{1}$, Anthony H. DeCicco ${ }^{2}$, Virginia L. Stouffer ${ }^{3}$, Shahab Hasan ${ }^{4}$, Rebecca L. Rosenbaum ${ }^{5}$ \\ LMI, McLean, VA 22102 \\ and \\ Jeremy C. Smith $^{6}$ \\ NASA Langley Research Center, Hampton, VA, 23681
}

\begin{abstract}
As part of ongoing research, the National Aeronautics and Space Administration (NASA) and LMI developed a research framework to assist policymakers in identifying impacts on the U.S. air transportation system (ATS) of potential policies and technology related to the implementation of the Next Generation Air Transportation System (NextGen). This framework, called the Air Transportation System Evolutionary Simulation (ATS-EVOS), integrates multiple models into a single process flow to best simulate responses by U.S. commercial airlines and other ATS stakeholders to NextGen-related policies, and in turn, how those responses impact the ATS. Development of this framework required NASA and LMI to create an agent-based model of airline and passenger behavior. This Airline Evolutionary Simulation (AIRLINE-EVOS) models airline decisions about tactical airfare and schedule adjustments, and strategic decisions related to fleet assignments, market prices, and equipage. AIRLINE-EVOS models its own heterogeneous population of passenger agents that interact with airlines; this interaction allows the model to simulate the cycle of action-reaction as airlines compete with each other and engage passengers. We validated a baseline configuration of AIRLINE-EVOS against Airline Origin and Destination Survey (DB1B) data and subject matter expert opinion, and we verified the ATS-EVOS framework and agent behavior logic through scenario-based experiments. These experiments demonstrated AIRLINE-EVOS's capabilities in responding to an input price shock in fuel prices, and to equipage challenges in a series of analyses based on potential incentive policies for best equipped best served, optimal-wind routing, and traffic management initiative exemption concepts.
\end{abstract}

\section{Introduction}

$\mathrm{T}$ The Airspace Systems Program of the National Aeronautics and Space Administration (NASA) is directly addressing the fundamental research needs of the Next Generation Air Transportation System (NextGen), a substantial and long-term change in the management and operation of the current version of the U.S. air transportation system (ATS), the National Airspace System (NAS). NextGen policies will encompass all airports, airspace, commercial airlines, and other aviation operators under the authority of the Federal Aviation Administration (FAA), the civil aviation authority body of the United States.

The purpose of this research is to investigate system-wide ATS performance impacts due to ATS stakeholder behaviors - in particular, behaviors of U.S. commercial airlines - under the influences of NextGen and other potential future policies and technology. This task is challenging, because the ATS is a highly interdependent and

${ }^{1}$ Consultant, Operations and Cost Analysis, 2000 Corporate Ridge, AIAA Member.

${ }^{2}$ Consultant, Operations and Cost Analysis, 2000 Corporate Ridge.

${ }^{3}$ Program Manager, Operations and Cost Analysis, 2000 Corporate Ridge, AIAA Senior Member.

${ }^{4}$ Program Director, Operations and Cost Analysis, 2000 Corporate Ridge, AIAA Senior Member.

${ }^{5}$ Consultant, Operations and Cost Analysis, 2000 Corporate Ridge.

${ }^{6}$ Research Aerospace Engineer, Aeronautics Systems Analysis Branch, Mail Stop 442, AIAA Member. 
complex network of systems and subsystems; operators, regulators, users, and the flying public; policies, procedures, and rules; and facilities and resources. A change in any aspect of this system has cascading effects, ultimately influencing the safety, performance, environmental impact, and economics of the ATS as a whole. These stakeholder-level decisions and behaviors have both a tactical and a strategic perspective, and they are influenced by socioeconomic, technological, and policy interactions.

The challenge of this research is to explicitly consider the behaviors of key stakeholders. This approach provides better insight into how NASA's technology research and development will be incorporated into the ATS, guides formulation of accompanying policies and incentives to ensure system performance is balanced with stakeholder perspectives, and reduces risk and uncertainty. The research will ultimately provide a tool for policymakers to assess policies and incentives to balance the objectives of all ATS stakeholders-FAA, commercial airlines, passengers, and other stakeholders - to achieve a more efficient, robust, and safer ATS by incentivizing desirable airline behaviors.

\section{Research Approach}

In a literature search we found a number of models and approaches that addressed aspects of our task objectives, but none treated them comprehensively. Some models and approaches assess impacts on the ATS from flight activity, but do not relate those impacts to airline decisions. Others address the dynamics of airline decisions, but do not apply the results to an ATS-wide impact analysis. Therefore, we determined that we needed to formulate and develop a research framework that assessed ATS-wide performance and impacts while accounting for airline and passenger decisions. This framework, called the Air Transportation System Evolutionary Simulation (ATS-EVOS), integrates existing NASA tools and resources and a new airline behavior model, the Airline Evolutionary Simulation (AIRLINE-EVOS), into a single process flow. This integrated approach was designed to best simulate responses by U.S. commercial airlines and other ATS stakeholders to NextGen-related policies, and in turn, how those responses impact the ATS. Figure 1 shows a high-level integration design of ATS-EVOS and the following subsections describe this process flow and its model components.

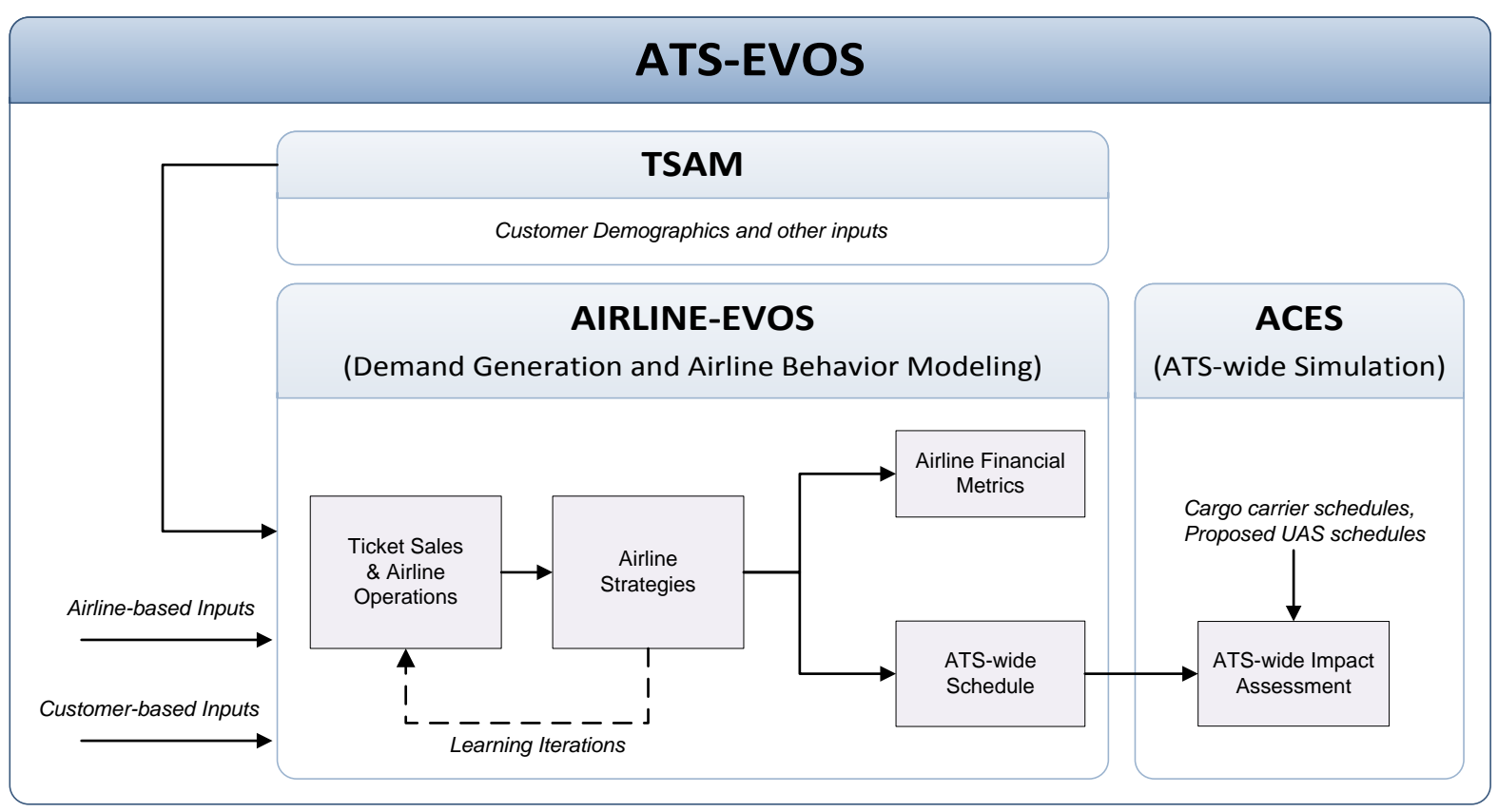

Figure 1. Overview of the ATS-EVOS Framework.

\section{A. ATS-EVOS Framework and Model Components}

ATS-EVOS is modular and uses different tools to address the modeling components of demand generation, airline behavior, and ATS-wide simulation to assess system performance. These modeling components are represented by the Transportation Systems Analysis Model (TSAM), ${ }^{1}$ and the Airspace Concept Evaluation System 
(ACES), ${ }^{2}$ respectively. Demand generation in ATS-EVOS was designed to capture aspects of specific market demand and characteristics of that market with respect to willingness to pay (WTP), to represent passenger buying behavior. These market demand mechanics are necessary for AIRLINE-EVOS to properly account for market changes as airlines compete, adjust airfares, and modify their networks. Currently, both AIRLINE-EVOS and TSAM are used to generate passenger demand, with AIRLINE-EVOS generating demand and TSAM being used to characterize the demand population. We are currently exploring ways to increase the role of TSAM in this functional capacity. Running AIRLINE-EVOS then results in an output of an ATS-wide flight schedule that is based on airline actions in response to passenger demand. If a policy scenario experiment is being conducted, any policy costs and/or benefits are also accounted for in the flight schedule output by AIRLINE-EVOS. Finally, the schedule is run through ACES to simulate the ATS-wide performance of the AIRLINE-EVOS adjusted flight schedule. This completes one iteration of the ATS-EVOS process and may be repeated as necessary, with ACES providing feedback to AIRLINE-EVOS for additional airline agent learning to influence subsequent decision making.

All these tools are integrated and controlled by a programmed automation script, the ATS-EVOS Integration Script (AIS), which executes the model components in sequence, processes outputs to be used as inputs to the next modeling step of the process, and cycles through any specified iterations. Any of the specific models we have mentioned thus far could in theory be exchanged for another that may provide some benefit to the scenario being investigated.

\section{B. Modeling Airline and Passenger Behaviors}

In the context of the ATS-EVOS framework, TSAM and ACES are established NASA models. We identified a gap where no existing model of airline behavior was available for integration into our approach, and developed AIRLINE-EVOS to fill that gap. As airlines are a driving entity in the ATS, AIRLINE-EVOS is intended to enable a better understanding of airline behavior and of the functional relationships airlines have to the other ATS stakeholders, both current (airlines, passengers, cargo carriers, FAA) and projected, such as operators of unmanned aircraft systems (UASs). We recognized that we also needed to model passenger behaviors, because airlines are profit maximizing entities and passenger decisions for ticket purchases significantly affect airline behaviors. In the use of AIRLINE-EVOS, we seek to explore how changes - regulatory or technological—affect the airlines, and how airlines, in turn, react and affect the ATS and its stakeholders.

AIRLINE-EVOS employs an agent-based approach to simulating airline behaviors, ideal for the complex system interactions in the ATS. The agent-based approach naturally accommodates modeling the multiple independent, heterogeneous entities, or agents, within the ATS that interact in specific ways. Agents follow predefined and often simplified rules that are designed to emulate real-world counterparts (airlines, passengers, air traffic control, airports). By representing simple behaviors at the agent-level, emergent dynamics can be observed from a system perspective as the agents interact with each other. We identified the key behaviors that airlines could be expected to exhibit in response to policy changes and new technologies. At a high level, only two primary behavior responses are directly available to the airlines: airfare pricing strategies and schedule-based strategies. Accounting for this, airline agents are adaptive, making tactical and strategic changes to their airfares and schedules under the influence of reinforcement learning, to best enable themselves to generate profit and compete in markets. For example, airline agents dynamically change airfares as time gets closer to the departure date, based on the ticket purchase date, and seating availability at the time of purchase. They adjust the flight schedule by changing the equipment assignment, or in other words, swapping assigned aircraft equipment between flights. Passenger agents choose to purchase their most preferred ticket based on their objectives and mission, subject to some randomness, used to model non-utility maximizing behaviors and irrationality.

Figure 1 illustrates, at a high-level, how AIRLINE-EVOS operates, using data inputs for airlines and passengers to execute a looping process within the model. This iterative process models airlines selling tickets and responding to both the market and competition, adjusting airfares or flight schedules to maximize profits. Iteration loops create as a learning opportunities; the airline agents determine the success of implemented strategies and, on the basis of their assessment, continue or end the strategy and try new ones. The outputs from AIRLINE-EVOS are adjusted flight schedules, which are used for assessing airline-specific operational performance as well as ATS-wide performance, and airline-specific financial metrics, which are used for assessing airfares, market trends, and airline financial performance.

This research is ongoing and while the functionality exists for full execution of the ATS-EVOS process, the current research has been focused scenario-based experiments that were used to verify and validate the operation of the ATS-EVOS framework and the AIRLINE-EVOS model. The remainder of this report will focus on the description of AIRLINE-EVOS and how it was used in our experiments, and it does not include ACES results. 


\section{AIRLINE-EVOS Model Description}

We now describe AIRLINE-EVOS, along with its general formulation, using a standard protocol known as ODD (Overview, Design concepts, and Details). ${ }^{3,4}$ ODD was designed to create factually complete and easily understood model descriptions that are standardized and consistent. ${ }^{5}$ What we present here is an abbreviated ODD; readers should reference our full report to NASA for the complete ODD description. ${ }^{6}$

\section{A. Overview}

\section{Model Purpose}

The purpose of AIRLINE-EVOS is to formally model airline behaviors, accounting for their response to passenger ticket purchasing choices and other external environmental factors-such as NextGen and FAA policy implementations - to enable the analysis of consequential, systemic impacts on the ATS as a whole and with respect to the system stakeholders.

Table 1. Passenger agent state variables.

\begin{tabular}{|c|c|}
\hline State Variable & Description \\
\hline Desired O-D travel & $\begin{array}{l}\text { Customers are instantiated in groups, as segmented by TSAM, each with a specific } \\
\text { O-D pair. For each agent, we assign an appropriate origin airport and destination } \\
\text { airport matching the O-D pair of the group they were instantiated from. }\end{array}$ \\
\hline Traveler type & $\begin{array}{l}\text { Decisions made by customers are motivated by the type of traveler they are, } \\
\text { categorized in AIRLINE-EVOS as either business or leisure. TSAM segments } \\
\text { each O-D demand forecast by the same traveler type categories, enabling us to } \\
\text { assign each agent with a traveler type according to the ratio determined by TSAM, } \\
\text { during the AIRLINE-EVOS instantiation. This state variable will be a factor in } \\
\text { determining a customer's advance purchase time, arrival time sensitivity, and } \\
\text { airfare price sensitivity. }\end{array}$ \\
\hline Household income & $\begin{array}{l}\text { TSAM further segments each O-D demand forecast into five income range } \\
\text { brackets. We use this segmentation of the demand to derive a specific income from } \\
\text { the ranges for each customer agent. }\end{array}$ \\
\hline Value of time & $\begin{array}{l}\text { We quantify an approximation for perception of the value of time of each customer } \\
\text { agent, to be used in the decision-making process for a customer to select an airline } \\
\text { ticket to purchase. It acts as a weighting coefficient that makes more inconvenient } \\
\text { itinerary options less attractive to customers (i.e., longer travel time durations, } \\
\text { including distances and connecting flights). By approximating an hourly value of } \\
\text { time, we can monetize the cost perception of a particular ticket in the customer } \\
\text { utility function. }\end{array}$ \\
\hline Advance purchase time & $\begin{array}{l}\text { Tactical airfare pricing strategies by airlines are assumed to be a function of } \\
\text { several factors. One significant factor is how early a customer decides to purchase } \\
\text { a ticket prior to the actual departure date. This state variable for each customer is } \\
\text { considered in the airline agent logic for adjusting airfare offerings for a specific } \\
\text { customer. }\end{array}$ \\
\hline Departure time preference & $\begin{array}{l}\text { We assume that departure time preference is a factor in the customer's ticket- } \\
\text { choice decision; this agent-specific value is used to evaluate ticket choices, } \\
\text { weighting their preferences toward itinerary options that depart closest to the } \\
\text { preferred departure time or earlier. We use this variable to capture the general } \\
\text { behavior of business travelers; when leaving home, they take flights early in the } \\
\text { day, and when returning home, they take flights later in the day. Leisure travelers } \\
\text { are assumed to be insensitive to the travel time. }\end{array}$ \\
\hline Airfare sensitivity & $\begin{array}{l}\text { Airfare sensitivity reflects how significant airfare is to the customer, which is } \\
\text { specific to the traveler type. Higher price sensitivity means that a customer cares a } \\
\text { great deal about price and wants to spend less money. This state variable is an } \\
\text { input into the customer's determination of the most preferable ticket choice. }\end{array}$ \\
\hline Willingness to pay & $\begin{array}{l}\text { WTP is used in the ticket choice submodel of the customer agents to generate a } \\
\text { subset of all offered tickets whose airfares are acceptable to a customer agent. }\end{array}$ \\
\hline Wealth & $\begin{array}{l}\text { This measure is an approximation of customer wealth, which we assume is } \\
\text { separate from income, though highly correlated. Measure of wealth is used in the } \\
\text { airline ticket choice submodel. }\end{array}$ \\
\hline
\end{tabular}




\section{Passenger Agents and State Variables}

The model has two different entities: passengers and airlines. They are modeled as distinct agents that behave autonomously and interact with each other, accounting for influences and constraints introduced by specified external factors. We first discuss passenger agents.

Passenger agents are modeled as heterogeneous agent populations, with a number of differentiating attributes, including the origin-destination (O-D) pair that defines the agent's desired route. In the current version of AIRLINEEVOS, their behavior is strictly concerned with making a decision about whether to purchase an airline ticket, and which ticket to purchase. Modeling that behavior requires (1) a passenger population based on forecasted demand, (2) relevant state variables, and (3) agent behavior logic for identifying feasible candidate ticket options and selecting a ticket from among those candidates based on preferences specific to the agent. After selecting airline tickets, the role of the customer passenger agents in the model has been satisfied

AIRLINE-EVOS instantiates multiple passenger populations at the beginning of each model run, each unique in size and specific to an air travel market defined by an O-D pair. The model uses market demand curves generated from previous research on market elasticities ${ }^{7}$ - specific to O-D pairs and to the type of travel, business or leisurewhich determines the number of potential passengers that may buy tickets, as well as the amount each passenger is willing to pay for a single ticket. Thus the passenger willingness to pay attribute is integrally linked with the size of a market's demand. In this way, we approximate passenger decisions to not purchase a ticket if all of the offered airfares are more expensive than the maximum amount they are willing to pay.

We use TSAM results to assign passenger agent-specific attributes, derived from how TSAM segments its output. In particular, we are interested in demographics of passengers in each air travel market, including leisure or business traveler status, and the distribution of household income among those two categories, all of which is provided in TSAM output. The passenger agent state variables used in AIRLINE-EVOS are described in Table 1.

Passenger agents possess only one decision-making behavior. They select which available ticket they will purchase, based on a cost- and inconvenience-minimizing utility function, with some degree of randomness. We assume that passenger agents are not completely rational and, therefore, with some random probability, do not strictly maximize their utility decisions. These behaviors are discussed in more detail in the submodels section.

\section{Airline Agents and State Variables}

The primary entities of AIRLINE-EVOS are airline agents. Airline agents possess behavior rule-sets that influence how they price their airfares and adjust fleet allocation in their flight schedules. They do so through an iterative learning process that involves both tactical and strategic decision logic. Modeling of these behaviors requires (1) generation or input of the airline agents, their starting flight schedules, and an initial allocation of aircraft equipment across the schedule; (2) relevant state variables; and (3) decision logic for dynamic airfare pricing, flight schedule adjustment, and equipage of new technology for airline fleets. Our current scope of effort is limited to airfare pricing changes, schedule adjustment through the swapping of aircraft, and equipage decisionson a subfleet basis - for a given technology set with cost and benefit assumptions specific to airline and subfleet type. The airline agent state variables used in AIRLINE-EVOS are described in Table 2.

Airline agent decisions are based on profit-maximizing utility functions and, as such, are dependent on ticket purchasing decisions by the passenger agents. That modeling enables a determination on how to allocate revenues and market share among the representative airlines being modeled and, subsequently, influences airline behavior responses for adjusting airfare or reallocating the aircraft equipment across the flight schedule. In the current version of AIRLINE-EVOS, these airline behaviors address the two primary responses by airlines to market forces: dynamic airfare pricing and strategic adjustment to the flight schedule. More specifically, airfare adjustment behaviors customize airfares to the specific passenger desiring travel, with respect to how close the ticket purchase is from the day of departure, and the number of seats available on the offered flight at the time of purchase. Schedule changes by the airline agents are strategic equipment gauging decisions that attempt to increase revenues by improving captured load factors.

Most other airline responses are executed over extended time frames, involve high capital costs, and require more complicated decision making, such as deciding on new aircraft purchases, leases, or refurbishment of the existing fleet. These actions will be investigated in future versions of AIRLINE-EVOS.

\section{Model Spatial and Temporal Scale}

The spatial scale is used to measure the flying distance, in nautical miles, between origin and destination pairs. The spatial scale is key for calculating metrics such as fuel burn and travel time.

Regarding temporal scales, AIRLINE-EVOS is dimensionless, meaning the duration of the time steps used during a model run is not specified. Time steps are required only during the learning iterations of the model run. 
Table 2. Airline agent state variables.

\begin{tabular}{|c|c|}
\hline State Variable & Description \\
\hline Airline & $\begin{array}{l}\text { We do not intend to model the behavior of a specific airline; rather, we model } \\
\text { proxy airlines that are representative of similar real-world entities with respect to } \\
\text { business model, network, operating costs, and aircraft fleet. Using ATS-wide } \\
\text { schedule inputs, airline agents are based on real-world airlines. Business models } \\
\text { are primarily full-service (FSC), low-cost (LCC), and regional carriers. }\end{array}$ \\
\hline Flight schedule & $\begin{array}{l}\text { Input flight schedules are a standard, real-world ATS-wide schedule, in ACES } \\
\text { schedule input file format (FDS- } 2 \text { or FDS-3). This input schedule includes the } \\
\text { following for every flight: origin and destination airports, aircraft type assigned to } \\
\text { the route, departure time, filed cruise speed and altitude, and route waypoints. }\end{array}$ \\
\hline Feasible set of flight itineraries & $\begin{array}{l}\text { Airline agents determine a feasible solution set of all possible itineraries for a } \\
\text { specific O-D pair, constrained to the airline's network as specified in the input } \\
\text { schedule for the given airline's real-world counterpart. Currently, our generated } \\
\text { itineraries are either nonstop or have one connection. }\end{array}$ \\
\hline Fleet inventory & $\begin{array}{l}\text { Each airline agent is assigned an aircraft fleet based on the actual fleet inventory } \\
\text { for their real-world airline counterpart, using Enhanced Traffic Management } \\
\text { System (ETMS) and Aviation System Performance Metrics (ASPM) data, or for } \\
\text { future time frames, projected fleet inventories. }\end{array}$ \\
\hline $\begin{array}{l}\text { Fleet allocation assignment to } \\
\text { the schedule }\end{array}$ & $\begin{array}{l}\text { We assign specific aircraft to the flight schedule according to the allocation } \\
\text { specified in the input flight schedule. }\end{array}$ \\
\hline Fleet age & $\begin{array}{l}\text { Each airline subfleet is assigned an average age, based on available online data, to } \\
\text { enable consideration of aircraft retirement in the model's equipage logic. }\end{array}$ \\
\hline Subfleet categorization & $\begin{array}{l}\text { AIRLINE-EVOS categorizes each subfleet based on the ease with which new } \\
\text { technology/avionics can be installed. In analyses for different equipage scenarios, } \\
\text { these categories are associated with specific costs for each category type. }\end{array}$ \\
\hline $\begin{array}{l}\text { Technological performance of } \\
\text { the aircraft fleet }\end{array}$ & $\begin{array}{l}\text { Aircraft performance variables (e.g., passenger capacity of the aircraft, cruising } \\
\text { altitude, speed, acceleration, and fuel burn rate during the climb, cruise, and } \\
\text { descent phases of flight) are assigned to each aircraft and then applied to each } \\
\text { flight accordingly. The capacity is used to track the number of available seats on } \\
\text { the route. The other metrics are used to calculate the aircraft's total fuel burn and } \\
\text { total travel time in the air. Variables are derived from Base of Aircraft Data } \\
\text { (BADA). }\end{array}$ \\
\hline Hedged fuel price & $\begin{array}{l}\text { Due to their unique business models and corporate strategies, each airline agent } \\
\text { has a different price that it pays for fuel. }\end{array}$ \\
\hline $\begin{array}{l}\text { Airline-specific operating costs } \\
\text { by flight }\end{array}$ & $\begin{array}{l}\text { Each airline agent is assigned a specific operating cost by flight, accounting for } \\
\text { nonfuel-related and fuel-related expenses. Nonfuel-related operating costs are } \\
\text { represented by operating costs per flying hour, based on Bureau of Transportation } \\
\text { Statistics (BTS) })^{9} \text { data, which is specific to the business model of the airline and the } \\
\text { aircraft type being flown. Fuel-related operating costs are based on the assigned } \\
\text { aircraft type, travel time, fuel burned, and airline hedged fuel price. This is a factor } \\
\text { in determining a flight's base airfare and the airline's profit determination. }\end{array}$ \\
\hline Airline-specific delay cost & $\begin{array}{l}\text { Each airline agent is assigned a specific cost of delay for each aircraft type in its } \\
\text { fleet, used for calculating monetized benefits from operational savings due to } \\
\text { delay reductions. }\end{array}$ \\
\hline Airline performance metrics & $\begin{array}{l}\text { State variables associated with airline performance metrics are dynamic and are } \\
\text { continuously updated throughout the AIRLINE-EVOS model run. The airline } \\
\text { performance metrics include available seat capacity by flight and load factor by } \\
\text { flight. }\end{array}$ \\
\hline Airline and flight profits & $\begin{array}{l}\text { For a given airline, profit is determined by a straightforward calculation of the } \\
\text { difference between the summed revenue and the operating costs, across every } \\
\text { flight that the airline operates on its schedule. This state variable is used as a } \\
\text { trigger mechanism for initiating airline behaviors. }\end{array}$ \\
\hline
\end{tabular}

Each iteration is reflective of a process in which airlines will assess their performance and make appropriate strategic changes to their schedule or pricing. In an iterative way, the market is then reengaged after any changes, and the airlines determine success or failure of those changes with respect to profitability. The outcome of this assessment influences subsequent strategy decisions by the airline. Each learning iteration loop is considered the 
next available time for the airline to publish and implement a flight schedule change; it is not a specified increment of time. It is also assumed that all learning iterations and the resulting model outcomes for experiment scenarios are within context of the same seasonal period of the starting schedule.

\section{Process Overview and Scheduling}

The dynamics of the model involve the processes that change the state variables of the model entities, describing who does what, in what order, and when the state variables are updated, specific to how time is being modeled. This process overview describes AIRLINE-EVOS, from the instantiation of agent populations, to their interactions, behavioral responses, learning iterations, and, ultimately, the generation of an adjusted ATS-wide flight schedule Fig. 2 shows a high-level modeling flow diagram that illustrates the AIRLINE-EVOS process, scheduling, and interaction points between the agents.

The process flow shown in Fig. 2 are described in the following steps:

Step 1. A passenger agent population is generated for each O-D pair based on market elasticity assumptions, calibrated to DB1B data, ${ }^{10}$ and assigned attributes based on TSAM demographics.

Step 2. An airline agent population is instantiated, based on predetermined representative airline business models. Each airline agent loads an initial flight schedule, aircraft equipment-related data, and fleet allocation assignments.

Step 3. Each airline generates feasible passenger itineraries for each O-D pair from the initial airline schedules.

Step 4. Passenger agents request itinerary options from the airline agents based on desired travel for a particular O-D pair.

Step 5. Airline agents evaluate the airfares of all the requested itineraries based on the advance purchase time and the remaining seat availability at time of purchase.

Step 6. Passenger agents choose tickets by maximizing utility, though they may randomly make an irrational choice. Steps 4, 5, and 6 are taken for all passenger agents, one at a time, in sequential order, based on the passenger's advance purchase time.

Step 7. Passenger purchases feed back into the airlines' airfare calculations as the supply of available passenger seats diminishes.

Step 8. As passenger buy tickets, metrics like seat availability and airline market share are tracked and updated for each flight and for all airlines as tickets are purchased.

Step 9. After all passenger agents have made their selection, flight level profits are calculated, and airline agents assess their current operational and financial state. Airlines may adjust their fleet allocation, including the gauging of scheduled aircraft, or change the base fare price in individual markets. New technology equipage decisions are also made at this point in the AIRLINE-EVOS process.

Step 10. For each type of airline strategy implemented, a feedback loop is executed in which the same passenger agent population is reengaged to consider the resulting new set of itinerary and airfare options, and a new profit result is calculated. This is representative of an airline trying to improve its performance by testing new schedule and airfare strategies at the next available incremental schedule change opportunity. It is a "learning" process, repeated for some user-specified number of iterations.

Step 11. The individual airline schedules are aggregated into one consolidated flight schedule, available for input into ACES, to simulate and explore consequential ATS-wide impacts of airline decisions.

\section{B. Design Concepts}

The ODD protocol identifies 11 design concepts that are key to robustly describing the dynamics and behaviors of complexity models we expect to observe. The following describes how AIRLINE-EVOS exhibits these design concepts.

\section{Basic Principles}

Central to AIRLINE-EVOS are the dynamic interactions between passenger choices, airline decisions, and the performance of the ATS as a whole. As illustrated in Fig. 2, airline agents interact by providing airfares and itineraries to passenger agents, and they evolve over multiple learning iterations through strategic pricing and scheduling changes that allow them to better compete in the market and gain revenue. 


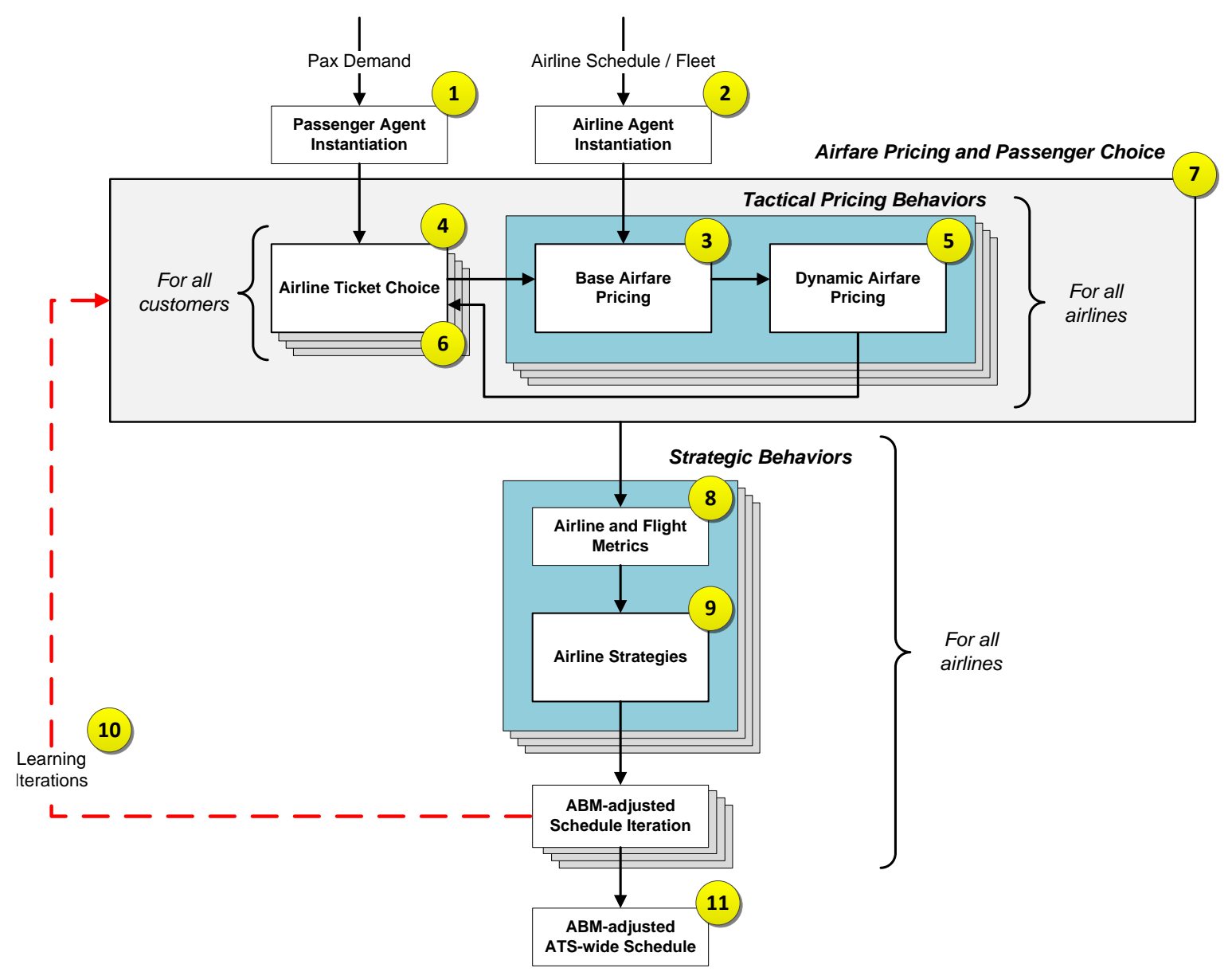

Figure 2. Overview of the AIRLINE-EVOS Process Flow.

\section{Emergence}

Airlines dynamically modify airfares as they are purchased, based on passenger advance purchase time characteristics and the available seats for a given flight, and this gives rise to several emergent behaviors in AIRLINE-EVOS:

- Market-based dynamics of passengers, with respect to purchasing behaviors over time and travel trends by traveler type and O-D pair (e.g., leisure travel on a decreasing trend in certain markets).

- Competitive airline behaviors, with respect to how airfares change over time, change in profit, and the resulting evolution of market share.

- Airline operations, with respect to load factor trends and equipment gauging by market, in addition to decisions to equip their fleets with new technology.

- Other emergent effects at the ATS-level are expected to result after running AIRLINE-EVOS schedule output in ACES. These operational-related performance metrics include measures of airspace congestion, delay, violation of safe separation, and others. 


\section{Adaptation}

The airlines alter schedules and airfares over time to account for changes in the competitive environment and the resulting suboptimal schedules.

- The airlines potentially sell different numbers of tickets for their flights during each iteration, which can result in financial losses at the flight level that can be corrected through changes to the schedule.

- The airlines change equipment assignments and modify ticket prices based on passenger purchasing behavior, which is in turn a reaction to airline schedule offerings. Airlines observe which itineraries are selling well and which are not, and swap aircraft between flights to best match scheduled offerings to demand. Likewise, airlines respond to passenger demand by raising or lowering prices. Competing airlines also make price and schedule adjustments, to the effect that when they are responding to passenger demand patterns, they are also responding to the competitive actions of other airlines.

\section{Objectives}

Airlines have the explicit objective of maximizing short-term profit. They make changes to their schedule and to ticket prices, then evaluate those changes based on their effect on profit. Passengers pursue their objective of maximizing their utility. In every iteration of the model, passengers explicitly choose the ticket that will maximize their utility, taking into account their individual preferences.

\section{Learning}

Airline agents change their adaptive traits over time. After all passengers have made ticket purchasing decisions during an iteration, airlines reassess the performance and profitability of previous changes to those behaviors and either abandon those changes and take a different approach, or they build on the previous changes to further improve performance and profitability. The airlines learn to make gradual changes to airfares, both to learn the ideal airfare for a particular market and to allow the airfare to drift when significant changes to the market affect the pattern of passenger behavior. Likewise, airlines make gradual changes to the schedule to better accommodate current market conditions.

\section{Prediction}

Predictive behavior is not present in the current version of AIRLINE-EVOS although there are plans for airline agents to include the ability to consider the impact of forecasted competitive behavior and market reactions before acting themselves, in addition to the iterative learning already modeled.

\section{Sensing}

Airlines have imperfect awareness of their environments. They know what tickets they have sold in the current iteration in response to the prices they have imposed, and they keep track of the seat availability of their own flights, as well as the amount of time remaining until departure, but they know little else.

\section{Interaction}

Airlines and passengers interact directly, with the airlines offering itinerary choices and airfares and the passengers choosing a ticket to purchase. Airlines also interact indirectly with each other, mediated through passenger ticket transactions that change the remaining unmet passenger demand in a market, a shared resource for which airlines compete.

\section{Stochasticity}

Stochastic processes, based on pseudorandom numbers, are used when assigning certain state variables to passenger agents (e.g., preferred departure time, traveler type), and when determining whether passengers will choose the ticket that maximizes their utility or act irrationally and choose an alternative ticket in a random manner.

\section{Collectives}

The current AIRLINE-EVOS has no collectives. Airline agents cannot be grouped by common traits, and each market defines a different, unique passenger environment. 


\section{Observation}

AIRLINE-EVOS currently employs extensive observation into processes in the model, most prominently through the use of logging statements, but also through special purpose output files created to generate a more processed form of quantitative output, ready for analysis and a final schedule file.

\section{Details}

\section{Model Initialization}

The state variables described for airline and passenger agents in Tables 1 and 2 are initialized to values derived from assumed distributions, point-value estimates, BTS data sources ${ }^{9}$, and other freely available information from the Internet. Please reference the full NASA report complete details of our model initialization assumptions. ${ }^{6}$

\section{Submodels}

Currently, AIRLINE-EVOS implements six submodels that enable agents to assess and interact with their environments. Table 3 describes the role and function of each submodel.

Table 3. AIRLINE-EVOS Submodels.

\begin{tabular}{|c|c|c|}
\hline Agent Type & Submodel & Description \\
\hline Customer & Airline Ticket Choice & $\begin{array}{l}\text { Passengers decide upon a ticket to purchase tickets from flights } \\
\text { matching their desired origin and destination. The Airline Ticket Choice } \\
\text { submodel models the passenger decision-making process by } \\
\text { mathematically modeling the utility of the individual tickets to the } \\
\text { passenger evaluating them. }\end{array}$ \\
\hline \multirow[t]{5}{*}{ Airline } & Flight Cost & $\begin{array}{l}\text { Airlines determine the operating costs of their flights, based on a number } \\
\text { of factors that include the technological performance specific to the } \\
\text { aircraft equipment being used on the flight. }\end{array}$ \\
\hline & Profit Calculation & $\begin{array}{l}\text { Airlines calculate profit at the flight and airline levels, the results of } \\
\text { which trigger behavioral responses by the airlines. }\end{array}$ \\
\hline & Dynamic Airfare Pricing & $\begin{array}{l}\text { Airlines adjust offered airfares depending on the time remaining until the } \\
\text { date of travel and on the number of tickets remaining to be sold for } \\
\text { individual flights. }\end{array}$ \\
\hline & $\begin{array}{l}\text { Airline } \\
\text { Equipment Swapping }\end{array}$ & $\begin{array}{l}\text { Once tickets have been sold, airlines may choose to switch equipment } \\
\text { for flights to better accommodate market demand or to better match the } \\
\text { equipage or performance profile to market and demand characteristics. }\end{array}$ \\
\hline & $\begin{array}{l}\text { Technology } \\
\text { Equipage Decision }\end{array}$ & $\begin{array}{l}\text { Airlines weigh, on a subfleet basis, costs and benefits for given } \\
\text { technology sets and decide if they will equip their subfleets. }\end{array}$ \\
\hline
\end{tabular}

The passenger ticket choice submodel, and the airline technology equipage decision submodel are worth discussing in more detail.

\section{Airline Ticket Choice Submodel}

Passengers choose the ticket that will minimize their disutility, although they may only purchase a ticket only if it is below the maximum price they are willing to pay (WTP). Passengers seek to balance the prices of fares while also choosing an itinerary that offers the least inconvenience in terms of its total travel time and closeness to the passenger's desired departure time. When passengers choose tickets, they each first identify a subset of itineraries that have an airfare below the passenger's WTP. Passengers then randomly determine whether they will rationally choose the ticket that would best satisfy their disutility function, given their own preference parameters, or whether they will instead irrationally choose an alternative with less than optimal utility. Irrational alternative choice probabilities are proportional to the distance (i.e., difference in utility) between the most preferable ticket and the worst alternative.

For passengers making rational ticket choices, each itinerary $i$ is evaluated by a passenger agent $g$, making a determination of the disutility value $U_{g i}$, as described in Eq. (1). This formulation was based on research by Mavris and Garcia. ${ }^{11}$

$$
\mathrm{U}_{\mathrm{gi}}=-\varphi_{\mathrm{gi}}\left[\mathrm{C}_{\mathrm{g}_{\mathrm{o}-\mathrm{d}}}\left(\frac{\text { Fare }_{\mathrm{i}}}{\text { Fare }_{\mathrm{MIN}_{\mathrm{i}}}}\right)+\mathrm{S}\left(\mathrm{T}_{\mathrm{g}}\left(\frac{\mathrm{FlyHr}_{\mathrm{i}}}{\text { FlyHr }_{\mathrm{MIN}_{\mathrm{i}}}}\right)\right)\right]
$$


This disutility function is a function of the ticket's associated airfare, the duration of travel associated with itinerary $i$, and the difference in the itinerary departure time from the desired departure time. The terms inside the brackets of the disutility function account for the airfare and the duration of travel. The first set of these terms in the brackets, normalizes the fare being evaluated against the lowest fare available for travel between the desired O-D pair. The airfare sensitivity coefficient $C_{g_{o-d}} C_{g_{o-d}}$ is specific to the traveler type of passenger $g$ and to the O-D market for itinerary $i$, and is a measure of the importance passenger $g$ places on fare in determining the best overall ticket.

The second set of terms inside the brackets, concerns the total duration of travel for itinerary $i$. Total travel duration is normalized against the shortest travel duration of all itineraries of the tickets being considered. The value of time coefficient $T_{g}$ is specific to passenger $g$ and is estimated from the household income attribute assigned to the passenger at instantiation. It reflects the importance passenger $g$ places upon total travel time in determining the best overall ticket. The $S$ term is a scaling factor that equalizes the difference between the different units for price and duration used within the utility brackets. The outside term $\varphi_{g i}$ acts as a penalty modifier in the calculation of itinerary disutility that accounts for any difference in desired arrival time and actual arrival time. In general, the more the arrival time of $i$ deviates from the desired arrival time of passenger $g$, the harsher the penalty.

\section{Technology Equipage Decision Submodel}

This submodel logic controls the airlines' evaluation when deciding whether to equip their aircraft with new technologies. The logic accounts for incentives that have varying levels of benefit depending on the amount of participating aircraft, and for incentives that only apply to select airports. The logic flow is as follows:

Step 1. For a single airline, identify an aircraft subfleet for possible equipage. If the benefit of the technology to be evaluated depends on the volume of participating aircraft, identify a combination of subfleets to be evaluated using one of the combinations in the subfleet power set. Each subfleet in the combination will be analyzed individually, but all will use the benefits estimate identified for the set of subfleet types.

Step 2. Calculate the benefit of equipage for the subfleet or subfleet combination by calculating the savings the aircraft would experience in terms of flight time if they were equipped.

Step 3. If the technology benefit depends on total equipage levels, identify a single subfleet in the subfleet powerset to assess for equipage.

a. Monetize the flight-time benefit for the subfleet by comparing the flight-time benefit with the costs of operating the subfleet. If the technology only affects flights at certain airports, benefit minutes are accrued only by those flight segments that arrive at one of the airports.

b. Calculate the network effects benefit by calculating the potential increased utilization of the network (the number of additional aircraft that could be fit into the airline's schedule) from the total flight-time savings of the subfleet.

c. Calculate the equipage cost (including installation, maintenance, and training) for the subfleet.

d. Given the total monetized subfleet flight-time and network benefit and costs, calculate the total savings.

Step 4. If the benefit of the technology being evaluated depends on the total level of equipage, aggregate the total savings among subfleets in the subfleet combination.

Step 5. Calculate the payback period, the amount of time before the airline sees a return on the equipage investment. If the total payback period is less than the airline's payback period tolerance, and no subfleet being evaluated will be retired during the payback period, the airline will choose to equip. Otherwise, the airline will not equip the subfleet or subfleet combination.

Step 6. Repeat step 1 for each aircraft subfleet or subfleet combination of every airline. 


\section{Analysis Scenarios}

A series of four scenario-based analyses were conducted to verify, validate, and refine our ATS-EVOS approach and the functionality and operation of AIRLINE-EVOS. The scenarios were designed to demonstrate the capability of AIRLINE-EVOS in quantifying the effects of new technologies, and of the effects of incentive policies.

\section{A. Quantifying the Effects of New Technologies}

We modeled airline evaluation of new technology through experiments in which we applied varying degrees of fuel cost changes. Our assumption was that any new technology would influence the airline's operating costs of service. By instituting changes in the fuel costs incurred, we could verify and validate the airline behavior responses to the associated financial impacts.

Fuel costs may affect airlines in different ways depending on their business model and cost structure. In this analysis scenario, we investigated, from an economic perspective, how airlines would adjust airfares given the implementation of modifiers across all airlines that lower and raise fuel costs. These modifiers were applied to each airline-specific fuel cost per gallon derived from BTS Form 41 data. ${ }^{9}$ We evaluated airline response to a series of global fuel cost multipliers: $0,0.5,0.75,1,1.25,1.5,1.75$, and 2 . The 1 multiplier is the baseline case. Values less than 1 reflect drops in fuel cost, and those greater than 1 represent increases.

This baseline case was used as our control scenario. We achieved what we deemed was sufficient validation of the control, against empirical data, to proceed with our initial analyses. The validation exercise found similar result patterns for real-world U.S. airfares and distributions of purchased ticket airfares as compared to appropriate DB1B data. In addition, AIRLINE-EVOS closely matched online data for the buying behaviors of passenger agents with respect to advance purchase time. ${ }^{6}$

\section{B. Quantifying the Effects of Incentive Policies}

The analysis of incentives examined the characteristics of human/automation and air/ground allocation of separation assurance and trajectory management functions, and their influences on airline behaviors. The scenarios we investigated modeled potential implementations of several incentives:

- best-equipped best-served (BEBS) preferences for higher-equipped aircraft,

- exemption from certain traffic management initiatives (TMIs) for aircraft equipped for self-separation, and

- wind-optimal preflight trajectory planning for aircraft equipped for self-separation.

These experiments were designed to assess airline agent decisions for equipping in response to incentive policy benefits. In all three of the equipage scenarios, we assumed the required technology was Automatic Dependent Surveillance-Broadcast (ADS-B) In/Out and Cockpit Display of Traffic Information (CDTI) to enable self separation by equipped aircraft. We now present a brief description of the operational benefits we assumed for each incentive policy concept.

\section{BEBS Incentive Scenario}

We defined a scenario that models the BEBS incentive using, as an example, a potential domestic airspace implementation of PTM-D, which is essentially pair-wise self-separation that has been initiated by the controller. PTM-D - as described to us by Ken Jones from NASA Langley Research Center - is an ATM concept that relies on both ADS-B In and Out to reduce inefficiencies in leader-follower traffic configurations in the airspace through delegated separation. For example, PTM-D may aid in the execution of specific miles-in-trail (MIT) initiatives, reduce pair-wise separation on congested air routes through specific sectors, and/or assist merging of aircraft from busy departure airspace into the en route environment.

Each of these represents potential gains in efficiency to the aircraft operator, which could lead to reduced operational costs due to reduced flying time. From all possible benefit mechanisms of PTM-D, we selected terminal arrival flow management as an easily identifiable and tractable benefit to model; incentive estimates for this scenario will be based on efficiency gains - reduced pair-wise separation — for arrivals in the terminal airspace.

Our modeling of the reduced pair-wise arrival spacing is indirect; that is, we model what we believe the effect of the technology would be on flights for this particular terminal airspace efficiency scenario. Direct modeling differs from the effects analysis of the indirect modeling approach and represents exploration of detailed interactions of reduced pair-wise arrival spacing to independently discover the impacts. In part, we chose reduced pair-wise arrival spacing benefits because we could base the initial value of the benefits on known impacts of tightening up an arrival stream using ADS-B and CDTI. Tightening an arrival stream of equipped aircraft was operationally tried at 
Louisville, KY, using the United Parcel Service (UPS) fleet, and resulted in several minutes of reduced terminal delay per flight. We emphasize that we expect this to be a conservative estimate of all the effects possible under the PTM-D concept, and that our benefit estimates are not at the level of detail that would be required to properly evaluate the full merits of the PTM-D program.

The BEBS scenario provides that the greater the level of equipage, the greater the realized benefit. When one aircraft in the arrival queue tightens the spacing, that aircraft saves some amount of time. If two or three aircraft are in direct sequence, the amount of time saved by the last aircraft is greater. If each aircraft tightens the spacing by 20 seconds, then the third aircraft in a row arrives 1 minute earlier. So the benefit of reduced pair-wise arrival spacing increases as the number of aircraft equipped increases. Non-equipped aircraft will benefit to some extent, but equipped aircraft have greater certainty and greater ability to capture the efficiency savings.

This scenario was evaluated for two time frames; we used input schedules and data from the year 2009 to represent a current time frame, and we assumed inputs projected for the year 2020 to represent a future time frame. The year 2020 was selected in order to avoid underestimating BEBS benefits. Pair-wise arrival spacing benefits will be maximized once the year 2020 has been reached, since that is the deadline for the FAA's mandate that all aircraft to be equipped with ADS-B Out. Pair-wise arrival spacing benefits would be reduced in a more near-term future year, because of mixed equipage in the airspace. For each time frame, we conducted a cost-benefit analysis to estimate technology equipage costs for PTM-D enabling technology (ADS-B In and CDTI), specific to aircraft type, and monetized our benefit assumptions to the airline if they equipped. The benefit estimates were derived from a series of Monte Carlo simulations of varying equipage levels against typical traffic mixes in a previously developed LMI airport capacity model. ${ }^{6}$ The resulting equipage-to-benefit relationships were formulated into Eq. (2) and (3) to calculate reduced delay benefits of equipage, reflecting the current and future time frames respectively.

$$
\begin{aligned}
& \text { DelaySavingsBenefit }=5.9259\left(\text { equipLevel }_{\text {follower }}\right)+2.0926\left(\text { equipLevel }_{\text {follower }}\right)^{2} . \\
& \text { DelaySavingsBenefit }=7.1368\left(\text { equipLevel }_{\text {follower }}\right)+0.767\left(\text { equipLevel }_{\text {follower }}\right)^{2}
\end{aligned}
$$

The expected benefit from reduced delays are monetized, specific to the airline realizing the gain, providing a seed benefit value to emulate the airline equipage decision. Airline agents would balance their operational costs, profits from ticket sales, competition, and estimated capital expense to equip aircraft with the necessary technology to make decisions about adopting the new technology and participating in the BEBS policy. Additional patterns related to the equipage rates of airlines also may need to be considered, such as market share or frequency of service.

None of the airline agents chose to invest in the NextGen technology under the BEBS incentive in the current time frame analysis; equipage costs far outweigh the average benefit to the equipping aircraft. A subset of aircraft in an airline subfleet may experience significant benefit from the equipment, but the airline agent equipage decision (in accordance with typical real-world practice) assumes that airlines will either equip an entire subfleet or will not equip any aircraft of that type. ${ }^{6}$ In the future time frame analysis, 9 of 44 airline agents choose to equip their aircraft. The primary impetus for this change in decision is that equipage costs decrease dramatically in the future scenario, to around one-fifth or one-sixth the cost of equipage in the current scenario. Also, the future scenario assumes a fuel price increase of 1.67 times the current airline fuel prices, which also had some impact. ${ }^{6}$

\section{TMI Exemption Incentive Scenario}

We defined a TMI exemption incentive scenario that may be enabled through various different concepts; one such example is the Autonomous Flight Rules (AFR) ${ }^{12}$ concept. Automated separation has the potential to mitigate some flight constraints that have been established to ensure safety in a human-centered system for traffic separation. The regimentation of traffic flows and limits on the number of aircraft in a sector would conceptually not be necessary in an automated separation system. NASA has pursued automation of the separation process at both the Langley and Ames Research Centers. The airborne solution studied at the Langley Research Center evolved into what is now called AFR.

AFR, a concept to enable self-separation, takes advantage of the surveillance available in aircraft resulting from the ADS-B mandate, and places the automated separation responsibility on the aircraft. The benefit of distributed separation workload accrues to air traffic control (ATC). Because the equipment needed to enable distributed selfseparation through AFR needs to be purchased by aircraft owners, and because that equipment is expensive, it has been proposed that AFR-equipped aircraft be exempted from MIT restrictions, be given preferential ground stop 
release, or both. The TMI exemption is an explicit-reward form of the BEBS concept, with the benefits being given to equipped aircraft as a reward. The benefit takes the form of reduction of variability in flight schedule delays.

Under AFR, the aircraft are self-separating and thus the air traffic controller would not need to manually separate them, reducing the workload for the sector controller and increasing the sector's capacity by the number of these self-separating aircraft. The self-separating aircraft would be relieved of having to follow MIT restrictions leading up to and through the sector.

Our modeling of a hypothetical TMI exemption incentive is based on what we believe the effect of the technology would be on flights for this particular terminal efficiency scenario. It does not represent detailed modeling of interactions of individual flights and controller workload to independently discover the impacts.

From sampling of more than 300,000 metering records in the TMI database at the system command center, we know that arrival times of traffic-metered flights are highly variable. ${ }^{13}$ At least 55 percent of metered flights arrive late from their metered required time of arrival (RTA); the mean arrival is 4.6 minutes late. Forty-nine percent of flights arrive more than 15 minutes late or more than 5 minutes early. This means that in addition to the delays imposed by the traffic system, most aircraft experience additional delays, likely caused by coordination difficulty related to reentering coordinated traffic flow.

En route MIT restrictions imposed an average of 1 minute of delay per flight per year, in an FAA study of national MIT restrictions. ${ }^{14}$ Airport ground stops are less frequent and affect less than 10 percent of traffic.

Taken together, MIT exemption and ground stop exemption - which occur randomly and with high variability throughout the year-affect all flights by an amount we have estimated as 2 minutes per aircraft day. We monetized the value of those minutes to create the benefit of TMI exemptions for the equipage decision.

We analyzed this scenario for two time frames, one representing the current system and the other representing the future system. We base the current system on our reference year of 2009, and used the associated inputs for that year, including flight schedule, TSAM estimates, subfleet operational costs, and fuel price. We define the future system as representing 2020, using updated model inputs for the future time frame. We assume an explicit 2-minute delay savings per day under the TMI exemption. The airlines compared the aggregated and monetized savings due to subfleet equipage against the equipage costs in making an equipage decision.

In the current time frame analysis, only one airline equipped any of its subfleets. ${ }^{6}$ The future time frame analysis equipment costs are approximately halved, while fuel price increases by about 67 percent, to about $\$ 1.11$ on average. These two factors are enough to convince the airlines that the equipage required for the TMI exemption is worth the investment; approximately 90 percent of the system-wide fleet makes a decision to equip. ${ }^{6}$

\section{Wind-optimal Routing Incentive Scenario}

For this scenario, we considered cost savings to airlines and subsequent decisions if wind-optimal routes were available to suitably equipped aircraft. Our scenario assumptions were based on a previous study for NASA, in which LMI investigated the benefits and costs of an optimal flight routing utility that accounts for wind speed and convective weather. ${ }^{15}$ Using flight records from ETMS, we re-planned wind-assisted great circle paths of each flight through four dimensions (latitude, longitude, altitude, and time) above flight level 240. This flight level restriction was chosen to avoid over-selecting wind routes for potential benefits. We chose a clear weather day in the NAS, October 10, 2010, as our subject day, as it was free of significant other delays and weather activity in the NAS.

The utility looked for the most efficient route across a Center, flight by flight, and requested flight amendments when the optimal routing would save an aircraft 1 minute of flight or more. We also examined the extent to which aircraft routes could be expected to "chase" the wind. We observed that jets would generally have to fly far off their intended flight path to pick up a large tailwind; generally, diversions of more than 50 miles did not result in net savings, demonstrating that it did not pay to tactically chase wind. Note that several flight routes exist between any city pair, and airlines typically request a near-optimal flight plan that takes into account the expected wind forecast for the day. Accordingly, we observed no changes to flight routes to account for large wind differentials, because the airlines had already captured any wind-related benefits.

LMI also studied the maximum benefit obtainable from direct routing, then applied wind and convective weather in an optimization program to route aircraft to incorporate adjustments for wind and to avoid convective weather. The output of this study was a set of flight plans. We artificially created "pseudo-TZs" along each flight's trajectory across Centers to provide latitude/longitude coordinates for modeling sector pierces. Those flight plans were available to run in ACES.

For this scenario, we assumed that delay savings are applied to all aircraft in the system and at all airports. However, the benefits are largely a function of the conditions of a particular day across the airspace, which we account for with a benefit probability factor explained in our section on benefit assumptions. We assume a mean benefit of 6 minutes of delay time savings, estimated for all equipped flights on approximately 95 percent of all 
days. This estimate comprises 2 minutes for self-separation — based on our estimates from the BEBS scenario-plus 4 minutes for wind. Each airline used the mean benefit estimate to evaluate each of their subfleets, one at a time

Similar to the BEBS and TMI exemption scenarios, we evaluated the scenario for two time frames, and assumed the enabling technology for using the optimal routes was ADS-B In and CDTI. A cost-benefit analysis was conducted for the wind-optimal scenario to allow airline agents to compare projected implementation costs against monetized benefits. We found that most subfleets would equip in both the current and future timeframes. ${ }^{6}$

Our modeling of wind-optimal routing is indirect; we very approximately model what we believe the effect of the technology would be on all flights taking advantage of the wind-optimal routing incentive. Ideally this modeling would be more direct, and explicitly represent detailed interactions of aircraft with wind-optimal routing equipment to independently discover the impacts. We emphasize that this analysis is an order of magnitude estimate of all the effects possible under wind-optimal routing, and that our benefit estimates are not at the level of detail needed to properly evaluate the merits of a full wind-optimal routing program.

In the current time frame scenario, nearly all airlines chose to equip all subfleets with technologies that allow them to make use of wind-optimal routing. All of the subfleets that were not chosen to be equipped were within 6 months of meeting the airline's maximum payback period of 2 years. In the future time frame scenario, all airlines equipped all subfleets. Although the wind-optimal route incentive generated significant savings in the current time frame scenario, the future scenario maintains approximately the same average benefit, while the installation costs are halved. ${ }^{6}$

\section{Results Summary}

The purpose of the four initial analyses was to generate preliminary model results, and provide insight into airline behavior in response to several hypothetical policy implementations. The studies were also intended to act as a robust $\mathrm{V} \& \mathrm{~V}$ exercise for AIRLINE-EVOS. We believe the studies provided both insight into airline behavior in the face of the hypothetical policies, as well as a challenging set of questions with which to test the model. The studies revealed areas that could benefit from improved data or additional model sophistication.

The fuel cost change scenarios found that model results largely followed expected trends, with airfares increasing as fuel costs increased. The results also helped support the theory that airlines whose fuel costs make up a larger proportion of their cost structure in comparison to nonfuel related costs-typically low-cost carriers-are affected more than airlines with a smaller proportion of fuel costs. We observed this trend through the percentage of passengers served, comparing it against the airline business model for all the fuel-cost multiplier scenarios. As fuel costs went higher, demand shifted to the full-service carriers-legacy carriers who primarily operate on a hub and spoke network-whose fuel costs are typically a relatively smaller component in their cost structure.

We also found that breakdown of results by haul-length were as expected, with long-haul routes showing greater sensitivity to fuel cost increases compared to short-haul routes. We intend to investigate these findings in more detail in our continuing research, in addition to exploring other ways of interpreting the influences of changes in fuel costs.

The equipage scenario studies found different results for the three potential NextGen equipage incentives: BEBS (using one of the benefits mechanisms expected with an implementation of PTM-D as the incentive), TMI exemptions (using sector count and ground stop exemptions afforded through concepts such as AFR for the incentive), and wind-optimal routing using assumed equipage benefits. Fig. 3 shows results for the current scenario (based in the year 2009), and Fig. 4 shows results for the future scenario (based in the year 2020). The results are shown as the number of subfleets that achieve ROI for their specific airline, binned by the number of months required to reach ROI. A comparison of the figures shows that the time frame scenario had a big impact upon the effectiveness of an incentive. Airlines chose to equip much more often in the future scenario, in which equipage costs were less, but fuel costs were higher. Both factors increased the profitability of equipage incentives that reduce total in-air flight time and, therefore, reduce operational costs.

Wind-optimal routing was by far the most successful incentive, with nearly all airlines equipping their entire fleet in the current scenario and all of them equipping their fleet in the future scenario. Equipage for the BEBS and TMI exemption incentives cost the same or less than the wind-optimal routing equipment, but the airlines' costbenefit assessment deemed that the lower associated benefits for those other incentives did not cover the cost of equipage.

The TMI exemption incentive was second most effective in incentivizing airlines to equip their aircraft, although apart from a single airline, none chose to equip in the current time frame scenario. However, in the future time frame scenarios, the majority of airlines chose to equip their aircraft to take advantage of the TMI exemption incentive. 
Although the TMI exemption was effective at incentivizing equipage in the future scenario, many subfleets did not result in benefits that meet the maximum payback period of 2 years, although it was close. In other words, the incentive did not result in the equipage of the entire system, but the incentive remained a strong economic force, pushing those unequipped subfleets toward equipage. For example, although the airlines might have been unwilling to accept only a partial subsidy for equipping those fleets without the incentive, the TMI incentive might cover the difference between the subsidy and the installation cost for many of those un-equipped subfleets. Likewise, anything that is expected to increase operational costs, such as increases to fuel price, is more likely to bring about equipage with that incentive in place.

Airline agents may have chosen to not equip under BEBS because they are not capable of comprehensively evaluating the resulting benefit. The magnitude of the hypothetical BEBS benefit that was implemented depended on the frequency with which compatibly equipped aircraft encountered each other at certain congested airports. More equipped aircraft at those airports means more benefits, regardless of which airline operates those aircraft. Thus, airlines must be able to take some estimation of their competitors' future actions into account to correctly estimate the percentage of equipped aircraft at the congested airports and, therefore, the benefit of the incentive. It is an inherently social task. Currently, the airline agents each assume that the world is in a steady state and make decisions in isolation; they are incapable of assessing their competitors.

\section{Conclusions}

The initial studies accomplished their original goals of providing insight, assisting in validating AIRLINEEVOS, and providing a test environment for continuing to mature the model. They've also demonstrated the unique potential of the AIRLINE-EVOS model for providing perspective on airline behavior, and it's affects upon the system. The studies have provoked a number of thoughts and ideas about the assessment and implementation of incentives to encourage improved system performance through NextGen equipment. Some of these ideas may point to future improvements to the model or to new research questions. 


\section{A. Significant Savings Through NextGen Incentives}

The projected monetized benefits that the NextGen equipage provides through the incentives of BEBS, TMI exemptions, and wind-optimal routing are potentially important. Provided that the benefits assessments of the incentives in the initial studies are reasonably accurate, enabling modifications to aviation procedures to achieve improvements like wind-optimal routes could have a significant effect upon the air transportation network in terms of saving money and resources and of increasing service to passengers. Theoretically, the delay reductions would decrease operating costs, which should enable airlines to increase profits by serving more passengers (whereas increases to costs generally force business strategies toward fewer enplanements at higher revenue per passenger). Likewise, the total flight-time reductions to the air transportation network could allow the addition of new flights to the schedule, further encouraging better service to passengers through additional enplanements. At some point, AIRLINE-EVOS could be used to verify this hypothesis.

\section{B. Simultaneous Implementation of Multiple Incentives}

In multiple scenarios, many of the subfleets that were not equipped by the airlines missed the return on investment cutoff by a small amount. One way to encourage airlines to equip those subfleets might be through simultaneous implementation of two or more incentives, rather than through subsidies. The advantage of such an approach is that in some cases, the installation cost of the combined equipment sets is much less than the sum of the installation costs of individual equipment sets, such as when combining incentives for our example implementations of BEBS and TMI exemption incentives. However, the benefit of simultaneous implementation of two or more incentives may not be greater than the benefit of the incentives implemented individually, since travel times can never be less than the unimpeded times for those routes. Nevertheless, a ROI could occur earlier using combined incentives and technologies given lower combined implementation costs and increased benefits over a single incentive, bridging the investment gap for those technologies.

\section{Implications of Current vs. Future Scenarios}

The difference in subfleet equipage frequencies between the current and future time frame scenarios is significant in the initial studies. In the studies, most airlines went from eschewing the new technologies in the current scenario, to almost universally adopting them in the future scenario. This has two key implications:

- In some cases, inaction may be more effective than a subsidy, particularly because the development and execution of any plan of financial subsidy will take time by itself.

- For some incentives, the airlines almost universally change their decision from not equipping in the current scenario, to equipping in the future scenario. In the real world, understanding the inevitability of future decisions affects how decisions are made in the present. It would be useful, therefore, to model how airline decisions would be affected by considering future responses to those same decisions.

\section{Significant Savings Through NextGen Incentives}

Some technologies or policies will inhibit NextGen equipage adoption. For example, policies enforcing higher standards for fuel consumption would reduce the concrete benefits of technologies and incentives that reduce flight time. Ultimately, the effect of incentives to encourage equipage, such as the three incentives studied in this research, would decrease. It may be worthwhile to conduct a mini-study to gauge the effects of competing policies and incentives upon each other and to investigate ways of implementing competing initiatives that take airline behavior into account to maximize the improvement of system behavior.

\section{E. Verification of the ATS-EVOS Framework}

These initial studies did not require runs through ACES, and so we did not make use of the full ATS-EVOS model suite for our analyses. However, using our integration script we incorporated TSAM data in an AIRLINEEVOS test run, and performed an automated loop in which an ACES runs took AIRLINE-EVOS outputs as an input. We plan to continue to develop this framework in our ongoing research and increasingly leverage this feedback loop to influence subsequent iterations through AIRLINE-EVOS.

\section{Acknowledgments}

This work was accomplished under NASA research announcement (NRA) NNH10ZEA001N, "Research Opportunities In Aeronautics-2010", Amendment 6, NextGen-Systems Analysis Integration And Evaluation Projected C.3 Subtopic 2: Comprehensive Modeling Of Air Carrier Behavior. Additionally the authors would like to 
thank Nelson Guerreiro, Jeff Viken, Kenneth Jones from NASA, William Cotton of Cotton Aviation Enterprises, and Vince Costanzo, for their counsel and advice.

\section{References}

${ }^{1}$ Baik H., and Trani, A. A. "A Transportation Systems Analysis Model (TSAM) to Study the Impact of the Small Aircraft Transportation System (SATS)" (presentation, 23rd International Conference of the System Dynamics Society, 2005).

${ }^{2}$ Sweet, D., Manikonda, V., Aronson, J., Roth, K., and Blake, M., "Fast-Time Simulation System for Analysis of Advanced Air Transportation Concepts," AIAA-2002-4593, American Institute of Aeronautics and Astronautics, AIAA Modeling and Simulation Technologies Conference and Exhibit, Monterey, CA, Aug. 2002.

${ }^{3}$ Grimm, V., Berger, U., Bastiansen, F., Eliassen, S., Ginotet, V., Giske, J., and et al., "A Standard Protocol for Describing Individual-based and Agent-based Models," Ecological Modelling, Vol. 198, Issues 1-2, Sept. 2006, pp. 115-126.

${ }^{4}$ Grimm,V., Berger, U., DeAngelis, D. L., Polhill, J. G., Giske, J., and Railsback, S. F., "The ODD Protocol: A Review and First Update," Ecological Modelling, Vol. 221, Issue 23, Aug. 2010, pp. 2760-2768.

${ }^{5}$ Railsback, S. F., and Grimm, V., Agent-Based and Individual-Based Modeling (Princeton University Press, 2012).

${ }^{6}$ Hasan, S., Horio, B. M., DeCicco, A. H., Stouffer, V. L., Goldsmith, J. H., Frank, A. B. and et al. Comprehensive Modeling of Air Carrier Behavior: 2013 Annual Report, NS308T3, McLean, VA: LMI, March 2014.

${ }^{7}$ InterVISTAS Consulting, Inc., Estimating Air Travel Demand Elasticities: Final Report, prepared for the International Air Transport Association, December 2007.

${ }^{8}$ Eurocontrol Experimental Centre, "Base of Aircraft Data (BADA) Aircraft Data: Revision 3.5,” EEC Note 09/03, July 2003.

${ }^{9}$ Department of Transportation, Bureau of Transportation Statistics, "Air Carrier Financial Reports (Form 41 Financial Data)," http://www.transtats.bts.gov/Tables.asp?DB_ID=135 [cited 16 March 2014].

${ }^{10}$ Department of Transportation, Bureau of Transportation Statistics, "DB1B Database," http://www.transtats.bts.gov/ Tables.asp?DB_ID=125 [cited 16 March 2014].

${ }^{11}$ Mavris, D. N., and Garcia, E., Decision Making Support for NASA's Aeronautics Research Mission Directorate, NAS102117, Contract 6075, March 2007.

${ }^{12}$ Cotton, W. and Hilb, R., "AFR User Implementation Costs and Strategies”, Report NASA/CR-2014-218247, September 2013.

${ }^{13}$ LMI, "D2 and Corner Cutter Analysis," presentation to NASA NextGen Systems Analysis, Integration, and Evaluation Project Manager, June 2, 2011.

${ }^{14}$ FAA, Data Link Benefits Study: National Sector Survey, Report DOT/FAA-ACD-32094/2.

${ }^{15}$ Stouffer, V., Hasan, S., Manley, B., Asensio, M., and Robinson, C. "Cost Benefit Analysis of a Near Term Implementation of Dynamic Weather Re-Routing Concepts and Technologies", American Institute of Aeronautics and Astronautics, Aviation Technology Integration and Operations and Multidisciplinary Analysis and Optimization Conference, Indianapolis, IN, September 17-19, 2012. 